\title{
Chapter 6. Mulching
}

S.M. Olson

Polyethylene mulch has been used for commercial vegetable production in Florida for more than 30 years (Fig. 6-1). There are approximately 70,000 acres of mulched vegetables in Florida, ranking it near the top in the U.S. for this production method. Almost all of the tomato and strawberry production is on mulch. Other crops that have considerable production on mulch are pepper, eggplant and various melons. Other crops such as squash, cucumbers or cauliflower have lesser acreage on mulch or are grown in a double crop situation.

\section{TYPES OF MULCH}

Florida growers use both low and high density polyethylene mulches. Thicknesses of mulches used vary from 0.5 to 2.0 mils. The most common colors used are black and white on black. Black is used traditionally during cool seasons since it tends to warm the soil by absorbing the heat of the sun and transferring the heat to the soil (Fig. 62). Black mulches also provide good weed control, except for the perennial nutsedges, if they are thick enough and do not allow light to pass through. White on black is used when planting and production occur during hot weather (Fig. 6-3). The white upper surface reflects the sun's energy and does not become heated, while the black underlayer prevents weed growth. Other mulches that are available and may be of potential use are described below.

Clear mulches increase soil temperatures the most since the sun's energy passes through the mulch and heats air and soil beneath the mulch directly and then the heat is trapped by the greenhouse effect. They have been used primarily in northern climates. There are problems with weed growth under the clear mulch, so fumigants or appropriate herbicides must be used. Clear mulches are not widely used in Florida.

Clear mulch has been used for bed solarizing, where the mulch is applied during the summer and allowed to remain for six to eight weeks. The mulch is painted white for fall production and black for winter production. Trials have shown that some weeds and diseases are controlled through solarization.
White mulches are warmer than white on black, but not as warm as black, since a portion of the sunlight passes through the mulch to heat the soil. Weed growth under white mulch can be a problem if fumigants or herbicides are not used.

Selective mulches come in various colors such as clear, brown or green, but all are semi-transparent or transparent. They are a new class of mulch which is wavelength selective. The mulch allows the wavelengths of light that will heat the soil to pass through (not as much as clear), but prevents weed growth by reducing the quantity of visible light (400 to $700 \mathrm{~nm}$ ) that is needed for photosynthesis, thereby negating the need for weed control under the mulch.

Degradable mulches have been tried in Florida for many years. Colors available include black, brown, white and clear. Most of the black and brown mulches are slightly transparent and allow some sunlight to pass through. One of the biggest problems with photodegradable mulches is the uncertain amount of time that is required for the mulch to reach the brittle stage. This sometimes results in the mulch breaking up long before expected. There is still the problem with the buried edge that must be brought to the surface and be subjected to the required exposure time to break up. Watermelon growers have used photodegradable mulches with mixed results.

Use of red mulches has received a lot of attention lately since there are reports of increased early and total yields and reduced nematode damage in tomatoes. Trials in both south central and northwest Florida have not confirmed the early or total yield increases when red mulch was used.

Other colored mulches that are available are yellow and silver. The yellow mulch has been used to reduce certain diseases. Silver mulch comes both as highly reflective types and mulches that are also gray especially if they are embossed. Trials with the gray mulch in fall production season in northwest Florida has resulted in reduced growth due to excessive soil temperatures. The reflective silver has benefits of reducing the incidence of certain diseases such as mosaic viruses in squash and tomato spotted wilt virus in tomatoes by affecting insect movement. 


\section{ADVANTAGES OF MULCH}

Increases early and (sometimes) total yields. One main reason for using a mulch is to promote faster crop development, earlier harvest and increased early yields. This is accomplished by selecting a mulch, such as black, which increases soil temperatures in the bed, enhances germination of seed, and promotes faster growth during the cool season. As north Florida growers receive more competition from growers in Georgia and South Carolina, they will need to adopt methods that result in earlier crops.

Inhibits weed growth. When black, white on black, red, selective or other dark mulch is used, very little weed growth occurs under the mulch. The mulches prevent light penetration or exclude certain wavelengths of light that are needed for the weed seedlings to grow, and they therefore die. None of the mulches will prevent the emergence of yellow or purple nutsedge and beds must be fumigated to control them.

Improves moisture retention. Mulch greatly retards the loss of moisture from the bed. As a result, a more uniform soil moisture regime is maintained and irrigation frequency may be reduced. Irrigation is still needed for mulched crops so that the soil under the mulch doesn't dry out excessively. The beds should be monitored on a daily basis, such as with tensiometers, to schedule irrigation needs.

Reduces fertilizer leaching. Since the fertilized bed is covered by the mulch, the fertilizer is less subject to leaching by rainfall (Fig. 6-4). As a result, the fertilizer program is more efficient and the potential exists for reducing traditional fertilizer inputs. Fertilizer can still be lost if heavy rainfall floods a field to the point where water is over the beds. When the water drains off, a portion of the fertilizer can be leached. This lost fertilizer can be replaced either with the drip system if using drip or with a liquid fertilizer injection wheel. Overwatering with a drip irrigation system can also result in fertilizer loss from under the mulch.

Decreases soil compaction. The mulch acts as a barrier to the pounding action of rainfall. This action can cause soil crusting, increased compaction and/or erosion. Less compacted soil provides a better environment for seedling emergence and root growth. When double-cropping, the reduced compaction can mean producing a second crop without disturbing the soil.

Reduces fruit rot. For vine crops, the mulch serves as a protective barrier between the soil and the fruit to reduce rot and keep the fruit cleaner. Mulch reduces rain-splashed deposits of soil and disease organisms for other crops such as tomatoes and eggplants.
Increases fumigant effectiveness. With some fumigants, such as methyl bromide, the mulch barrier is necessary for the fumigant to work properly. The water layer that forms under the mulch slows down the loss of the methyl bromide and allows the concentration to remain high enough to work effectively. With other fumigants, such as metham-sodium, the mulch increases the effectiveness by maintaining a critical concentration of fumigant in the soil.

\section{DISADVANTAGES OF MULCHING}

Requires specialized equipment. The mulch cultural system requires the purchase or construction of certain pieces of specialized equipment for laying the plastic and planting through the mulch. Most of the equipment cannot be used for other production systems. Equipment includes a bed press, mulch layer and mulch transplanter or seeder. The equipment ranges from inexpensive setups for small growers to very expensive setups for large growers doing multiple rows at a time. If a grower is handy in the shop, some of the equipment could be made on the farm.

Increases preplant costs. The added expense of purchasing the mulch increases preplant production costs and discourages some growers from using mulch. The cost of the mulch can range from as low as $\$ 80$ per acre for wide spacing and narrow beds to more than $\$ 200$ per acre for close rows and wide beds.

Requires removal and disposal. The biggest problems associated with mulch use are removal and disposal. Since most mulches are not degradable, they must be removed from the field after the cropping season (Fig. 6-5). The most common method is removal by hand, which involves cutting the mulch down the center and pulling it to each side and out of the ground. In tomatoes this is done before the strings are burned, and the plants are dropped on to the mulch. The heat of burning the strings ruins the integrity of the mulch and makes it difficult to pull up. There are machines available for mulch lifting and removal, but they usually require that the crop be removed and the beds be reasonably clean. Some growers in south Florida have been burning the mulch, but the buried edges still must be removed by hand. In some areas burning is prohibited by local laws.

Disposal presents a severe problem because of the volume of waste generated and the fact that mulch does not decompose. Many landfills reject mulch as unsuitable landfill material. At present, one manufacturer of mulch films will help coordinate the pick-up of the used mulch if it has been baled or compacted for use in recycled products. Another possible use of spent mulch under investigation is energy production. The mulch materials currently being used are nearly as high in energy value as fuel oil. 


\section{MULCH APPLICATION}

A normal sequence for mulch application as follows:

- Land preparation such as discing or plowing, no different from normal crop preparation.

- Applying fertilizer, soil insecticides or other pesticides and mixing uniformly.

- Forming the bed and pressing it, with fumigation and fertilizer banding that are normally done during this step.

- Laying the mulch along with the drip tube, if used.

Equipment is available that will accomplish the last three steps in one pass. Large growers that are doing multiple rows at a time may take from two to four passes over the field to finish the mulching process. If drip irrigation is used, all of the $\mathrm{P}$ and micronutrients are incorporated in the bed along with 20 to $40 \%$ of the $\mathrm{N}$ and $\mathrm{K}$. The remainder of the $\mathrm{N}$ and $\mathrm{K}$ will be applied through the drip lines. Fertilizer amounts are those indicated by a valid soil test.

As the mulch is being laid, the bed is pressed firmly so that later the bed does not collapse in the center and allow water to stand. The mulch should be laid so that it is in tight contact with the bed. This will help transfer heat to the bed when a dark mulch is used and will reduce flapping in the wind. Excessive flapping can result in seedling damage, tears in the mulch, premature breakdown of the mulch, or allow the wind to blow the mulch from the bed. It is critical to adjust the mulch layer so that the edges are buried sufficiently to prevent uplifting by wind. If fumigating, the knives should be checked regularly for plugging. Also, when drip tubes are used, they should be applied with the orifices pointing up so that plugging will be reduced.

\section{BED HEIGHT AND WIDTH}

Bed height is directly related to the amount of flooding potential in the field. In south Florida, traditionally beds are higher than in north Florida. Beds in south Florida may be 6 inches or more to keep the beds from becoming too wet, while in north Florida beds may be no higher than 4 inches. If there is no history of high water and the field slopes so water will run off, the bed only needs to be high enough to permit rain drainage from the bed surface and to facilitate tight application of the mulch on the bed. Excessively high beds are prone to rapid drying and can be difficult to re-wet, especially with overhead irrigation.

The width of the bed will depend upon several factors such as crop to be planted, reason for using mulch, and number of rows desired per bed. Normally, the mulch is 20 to 24 inches wider than the bed width. The extra width is needed to cover the sides of the bed and provide sufficient material for covering with soil so the mulch will be adequately anchored. The most common bed widths range from 24 to 40 inches. Some watermelon growers have been experimenting with narrow beds of 12 to 18 inches to save money on mulch costs. The narrow mulched beds provide for faster germination of the seed, enhanced early growth, and in-row weed control. Most growers are using overhead irrigation and sidedressing the melons outside of the mulched area. Tomatoes are commonly grown on 32- to 36-inch-wide beds, while crops such as peppers where two rows per bed are used require bed width of 36 to 40 inches. With vine crops, varying the bed width from 16 to 24 to 32 inches has no effect on yield.

In general, if the bed is not too wide nor too high, the mulch will not need to be perforated to facilitate irrigation and rainwater entrance. The roots should receive moisture by lateral movement through the soil under the mulch. Excessively punctured mulch can lead to fertilizer leaching, weed growth through the holes and tearing of the mulch by wind. Use of drip irrigation negates the need for perforation.

\section{CROP ESTABLISHMENT}

Vegetable crop establishment on mulches can be accomplished by transplanting or direct-seeding. Transplanting can be accomplished by mechanical plug planters or with semi-automated transplanters (Fig. 6-6). Both of these types require labor to be on the planter. Fully automated transplanters for planting through mulches are available. One of the most common transplanters used in Florida is the water-wheel transplanter. The water-wheel transplanter punches a hole, applies water or a fertilizer solution and a transplant is put in the hole and root ball covered with soil by hand. In-row spacing can be varied by changing the wheel or wheels, if a two-row planter.

Direct-seeding through mulch can be accomplished by hand, plug-mix or gel-mix planting, or mechanical seeders. Hand planting is usually practiced by small growers since it does not require any expensive equipment purchases. It is very costly for labor but usually very efficient in terms of seed use. With this procedure, both raw seed and plugmix planting have been used. Some method is required to space and punch the holes in the mulch.

Plug-mix or gel-mix planting utilizes a medium to suspend the seed to get a uniform seed density and provide ideal germination conditions. The medium is usually a finely ground mixture of peat and vermiculite alone or mixed with a gel material to prolong moisture retention. The most important part of plug-mix planting is in the mixing process, since uneven mixing will result in variable seed distribution and poor stands in the field. For small batches, a mortar mixer works much better than a cement mixer. After the seed and medium are mixed properly, the 
mixture is placed in the hopper of the planter where the machine punches or burns a hole in the mulch and places a small amount of the mixture into the hole.

There are numerous mechanical seeders on the market that are able to singulate seed and deposit them in a hole punched in the mulch. Some of the mechanical seeders are also able to utilize media to cover the seed. Several growers have modified plug-mix planters by adding precision hoppers to plant seed without the need for media. With high density plantings (such as double-row and close in-row spaced squash), the mechanical seeders are more economical to use than plug-mix planting because of the amount of media needed. Some mechanical seeders have the ability to lay mulch or row cover and seed in one pass.

\section{PRODUCTION SYSTEMS USING MULCH}

Mulch can be integrated into other production systems to enhance the effects of mulching (Fig. 6-7). Transplants used with mulch can help decrease the number of days to harvest and provide exact plant populations without thinning, which is often required when direct seeding. Windbreaks such as a small grain should be used to reduce wind damage, sandblasting, and to help reduce the cooling effect of wind.

Drip irrigation is compatible with mulching, because the grower can maintain optimum moisture under the mulch and the system can be computer controlled for water and nutrient application. Drip irrigation also provides for periodic fertilization of the crop so that large amounts of preplant fertilizer are not needed. Being able to provide the crop with nutrients as they are needed is a more efficient method of fertilization and reduces the potential for leaching losses of fertilizer. Use of the mulch for a second crop is made easier when drip irrigation is used. It is no longer necessary to apply extra fertilizer when planting the first crop to ensure adequate amounts for the second crop.

Row covers when used in conjunction with mulch produce the earliest yields for some crops such as melons but have not always proved beneficial for crops such as peppers or tomatoes. 